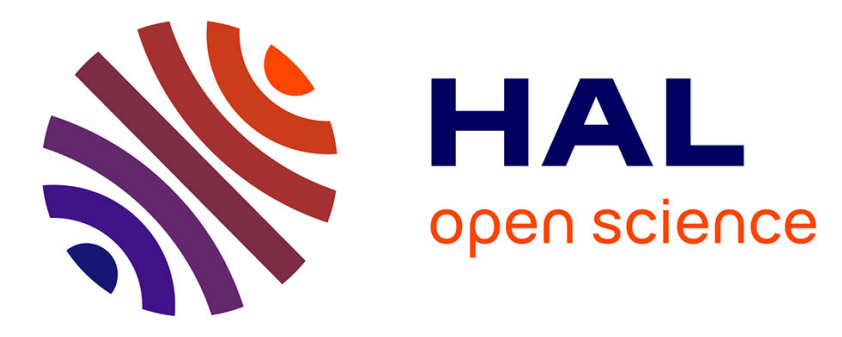

\title{
Investigation and modelling of the water transport properties in unfilled EPDM elastomers
}

Maxime Lacuve, Xavier Colin, Lara Perrin, Flandin Lionel, Petru Notingher, Christophe Tourcher, Mouna Ben-Hassine, Houssam Tanzeghti

\section{To cite this version:}

Maxime Lacuve, Xavier Colin, Lara Perrin, Flandin Lionel, Petru Notingher, et al.. Investigation and modelling of the water transport properties in unfilled EPDM elastomers. Polymer Degradation and Stability, 2019, 168, pp.108949. 10.1016/j.polymdegradstab.2019.108949 . hal-02429352

\section{HAL Id: hal-02429352 \\ https://hal.science/hal-02429352}

Submitted on 6 Jan 2020

HAL is a multi-disciplinary open access archive for the deposit and dissemination of scientific research documents, whether they are published or not. The documents may come from teaching and research institutions in France or abroad, or from public or private research centers.
L'archive ouverte pluridisciplinaire HAL, est destinée au dépôt et à la diffusion de documents scientifiques de niveau recherche, publiés ou non, émanant des établissements d'enseignement et de recherche français ou étrangers, des laboratoires publics ou privés. 


\title{
Investigation and modelling of the water transport properties in unfilled EPDM elastomers
}

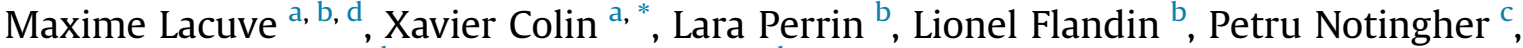 \\ Christophe Tourcher ${ }^{\mathrm{d}}$, Mouna Ben Hassine ${ }^{\mathrm{d}}$, Houssam Tanzeghti ${ }^{\mathrm{e}}$ \\ a Arts et Métiers ParisTech, PIMM (UMR CNRS 8006), 151 Boulevard de l'Hôpital, 75013, Paris, France \\ b Université Grenoble Alpes, Université Savoie Mont Blanc, CNRS, LEPMI (UMR CNRS 5279), 38000, Grenoble, France \\ c Université de Montpellier, IES (UMR CNRS 5214), 860 Rue de Saint Priest, 34095, Montpellier, France \\ d EDF Lab, Site des Renardières, Avenue des Renardières, Ecuelles, 77818, Moret-sur-Loing Cedex, France \\ e ENEDIS, Direction Technique, 34 Place des Corolles, 92079, Paris la Défense Cedex, France
}

Keywords:

EPDM

Water sorption

Diffusion and solubility

Henry and Fick's laws

Clustering

Park's law

\begin{abstract}
A B S T R A C T
The water sorption properties (i.e. diffusivity and solubility) of three unfilled vulcanized EPDMs were investigated in wet atmosphere (typically between 0 and 95\% RH) and in pure distilled water (denoted as $100 \% \mathrm{RH}$ ) at $70^{\circ} \mathrm{C}$ with an IGAsorp dynamic sorption analyzer. In the $0-0.5$ activity range, all EPDMs obey to the usual Fick and Henry's laws. In contrast, at activities higher than 0.5, the water sorption behavior of all EPDMs deviates from these two laws because of the formation of water clusters. Park's equation was used for simulating accurately the sorption isotherms and thus, accessing Henry's constant and the average size of water clusters. In wet atmospheres, clusters would be composed of about $8 \pm 4$ molecules corresponding approximately to the size of free volume holes. In contrast, in pure distilled water, clusters consist in a much larger number of water molecules (between 55 and 71) presumably because of an exacerbated swelling of EPDM samples. Thus, immersion in water solution is more drastic than exposure to fully saturated wet atmosphere. The impact of the EPDM formulation (nature and content of crosslinking agent) on these experimental results is clearly of the second order of magnitude.
\end{abstract}

\section{Introduction}

The performance and reliability of the electricity distribution networks is a major concern for its operators all around the world. Increasingly electrical cables and associated accessories are made of polymeric materials and the question of their in-service durability is an open issue. In particular, it is necessary to prevent the penetration of moisture up to the insulation layers because water could cause a dielectric breakdown. For this reason, manufacturers preferably use apolar polymers in their electrical cables and associated accessories products, such as polyethylene (PE) and its vulcanized terpolymers (Ethylene Propylene Diene Monomer (EPDM)), which are reputed to be almost hydrophobic [1-3].

If in apolar polymers, the equilibrium water uptake is effectively very low, in contrast, the water diffusion is very fast. The main reason for such a behavior is the almost total absence of polar groups (in general, very few oxidation products are formed during processing) playing the role of hydrophilic sites [4]. Since these sites establish intense interactions (hydrogen bonds) with water molecules, they are the main contributors to water absorption, but they also hinder the migration of water molecules into the polymer volume according to a three-step mechanism [5] (see Fig. 1).

According to this mechanism, the dissociation of the waterpolymer complex would be much slower than the migration of water molecules between two neighboring hydrophilic sites.

In the 80s, McCall and al [6]. performed desorption experiments with a highly sensitive electromagnetic microbalance (with a sensitivity estimated to $\pm 2 \mathrm{ppm}$ ) on low density polyethylene (LDPE) after immersion in pure distilled water. They showed that LDPE does not absorb more than $20 \mathrm{ppm}$ (i.e. $0.002 \mathrm{wt} \%$ ) of water, whereas its water diffusivity is about $7.5 \times 10^{-11} \mathrm{~m}^{2} \mathrm{~s}^{-1}$ at $25^{\circ} \mathrm{C}$. These authors also found that both quantities increase with the

\footnotetext{
* Corresponding author.

E-mail address: xavier.colin@ensam.eu (X. Colin).
} 
temperature according to an Arrhenius law $\left(\Delta \mathrm{m}_{\infty}=7.5 \times\right.$ $10^{7} \exp \left(-\frac{37600}{\text { RT }}\right) \mathrm{ppm}$ and $\mathrm{D}=2.9 \times 10^{-4} \exp \left(-\frac{37600}{\mathrm{RT}}\right) \mathrm{m}^{2} \cdot \mathrm{s}^{-1}$ respectively), thus reaching respectively about $142 \mathrm{ppm}$ (i.e. $0.014 \mathrm{wt} \%$ ) and $5.5 \times 10^{-10} \mathrm{~m}^{2} \mathrm{~s}^{-1}$ in current operating conditions of electrical cables and accessories (typically $70^{\circ} \mathrm{C}$ on the outer surface of the insulation layers).

However, to our knowledge, there is almost no information available for EPDMs in the literature, except for a few values of water permeability (i.e. product of $\mathrm{D}$ by $\mathrm{S}$ ) determined at low temperature close to room temperature for complex industrial formulations [7-10]. The question arises whether the experimental data obtained by McCall et al. [6] on LDPE can be simply transposed or not to unfilled EPDMs, of course, after having corrected them by the crystallinity ratio of LDPE (since crystals are considered impermeable to most gases and vapors). In fact, in the case of EPDMs, one can suspect several degrees of complexity.

On the one hand, it is well known that these elastomers are not totally pure but contain several vulcanization additives, some of them carrying polar groups able to establish intense interactions with water molecules (e.g. zinc oxide [11], stearic acid [12], or $\alpha$ cumyl alcohol originating from peroxide by-products $[13,14]$, etc.). What is the impact of EPDM formulation on water absorption? On the other hand, although the molecular interaction theory works perfectly for moderately (e.g. polycarbonates and polyesters) and highly polar polymers (e.g. polysulfones and amine crosslinked epoxies) [4], its application to apolar polymers seems very limited and even, questionable. Indeed, it would involve the knowledge of the precise nature of the polar groups interacting with water molecules. However, in apolar polymers, such groups could originate from oxidation products (in particular, hydroperoxides, hydroxyls and carbonyls) formed in very low concentration [6]. They are thus hardly detectable by conventional spectrochemical laboratory techniques (FTIR, NMR, etc.) because of their poor sensitivity threshold.

Otherwise, the free volume theory can be tentatively used to explain the water sorption behavior of apolar elastomers. This theory assumes the existence of a "mobile" nanoporosity allowing the migration of water molecules into the polymer volume [15-17]. In its simplest version, water molecules are assimilated to spheres of 1.43 Å radius [18] that can fill larger holes in polymers. The size of these holes can be estimated by different techniques, for instance swelling tests, $\mathrm{N}_{2}$ gas adsorption and thermoporosimetry [19-21], but the most accurate one seems to be Positron Annihilation Lifetime Spectroscopy (PALS) [22]. As an example, holes with an average volume of $25 \AA^{3}$ were evidenced by this technique in high density polyethylene (HDPE) [23]. Assuming, here again, a spherical shape, the corresponding average radius would be $1.8 \AA$, which would imply that only one water molecule could be inserted into a hole. This result does not seem absurd knowing that McCall et al. [6] found a classical water sorption behavior for PE.

In this rather simple case, it is generally assumed that the water diffusion obeys Fick's second law and thus, Crank's mathematical decomposition [24] is commonly used for determining the coefficient of water diffusion D from the slope at the origin of sorption or desorption curves $\left(\Delta m=\Delta m_{\infty} *[1-\right.$

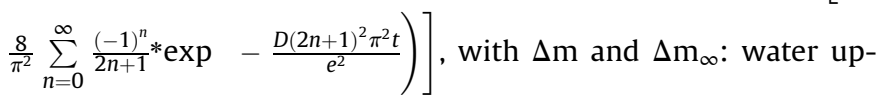
takes at time $\mathrm{t}$ and at equilibrium respectively, and e: sample thickness). In addition, Henry's law [25] allows accurately describing the linear shape of the sorption isotherms $\left(\Delta m_{\infty}=H^{*}\right.$ $a$, with $\mathrm{H}$ : Henry's constant, and a: water activity) throughout the whole activity interval (i.e. between 0 and 1 ).

In contrast, in vulcanized EPDMs, it is well known that free volume holes are much larger. Indeed, their average volume and radius are respectively $190 \AA^{3}$ and $3.57 \AA$ [26], thus offering the possibility to several (at least six) water molecules to be inserted into a hole. Literature even reports that the formation of water clusters is suspected to lead to peculiar sorption behaviors in polymers. In particular, they are responsible for the appearance of a positive concavity on the sorption isotherms at high water activities [3,27].

Many analytical models have been proposed to tentatively simulate this peculiar shape of sorption isotherms [28]. Some of them are purely empirical. Others have some physical bases, but either contain too many parameters to be identified from such simple curves, or poorly match the experimental data throughout the whole activity interval [27]. Shen \& Springer [29] suggest a semi-empirical power law with only two parameters to accurately describe the clustering effects $\left(\Delta m_{\infty}=B^{*} a^{n}\right.$, with B: an experimental parameter, and $n$ : average cluster size, i.e. average number of water molecules associated in clusters). Park [30] proposed to add this term onto Henry's law to describe the sorption isotherms throughout the whole activity interval $\left(\Delta m_{\infty}=H^{*} a+B^{*} a^{n}\right)$. This semi-model seemed to us to have the best compromise between simplicity and richness of provided information for analyzing and elucidating the water sorption behavior of the different EPDM insulation formulations of electrical cables used on the electricity distribution networks.

This study will involve two successive steps:

i) First of all, the determination of the sorption behavior of these materials directly in a climatic chamber equipped by a highly sensitive microbalance throughout the whole water activity interval at a temperature close to the current operating conditions of electrical cables and accessories (i.e. $70^{\circ} \mathrm{C}$ );

ii) Then, the analysis and simulation of the obtained sorption kinetics and isotherms with literature models, chosen with incremental increasing complexity (first Fick and Henry, then Park) in order to propose a realistic scenario for the moisture penetration into the insulation layers.

\section{Materials and methods}

\subsection{Materials and samples}

The starting EPDM gum was supplied by Dow chemical Co. under the reference Nordel IP 4520. This linear terpolymer is composed of $55 \mathrm{wt} \%$ ethylene, $42 \mathrm{wt} \%$ propylene and $3 \mathrm{wt} \%$ ethylidene norbornene (ENB) as diene monomer. Three macromolecular networks (representative of EPDMs used in cable junction applications) were elaborated: two were crosslinked with sulfur (denoted EPDM A and B), and one was crosslinked using dicumyl peroxide (denoted EPDM C). Their chemical composition is detailed in Table 1.

EPDM plates of about $0.6-0.7 \mathrm{~mm}$ thickness were press-molded and vulcanized at $170^{\circ} \mathrm{C}$ under a pressure of $20 \mathrm{MPa}$. The optimum duration for crosslinking each EPDM formulation at $170^{\circ} \mathrm{C}$ was previously determined using rheometry according the ISO standard 6502. This duration ( 10 min for A, 20 min for B, and 22 min for C) corresponds to the time required for the torque to reach $98 \%$ of its maximum value. For water sorption experiments, rectangular specimens of about $8 \mathrm{~mm}$ width and $10 \mathrm{~mm}$ length were taken from the plates using a specific cutting tool. 
Table 1

Detailed formulation in parts per hundred of rubber (phr) of the three EPDM elastomers under study.

\begin{tabular}{|c|c|c|c|c|}
\hline Function & Additive & EPDM A & EPDM B & EPDM C \\
\hline Elastomer matrix & EPDM NORDEL IP 4520 & 100 & 100 & 100 \\
\hline \multirow[t]{2}{*}{ Vulcanization activator } & $\mathrm{ZnO}$ & 5 & 5 & - \\
\hline & Stearic acid & 1 & 1 & - \\
\hline \multirow[t]{2}{*}{ Reticulation agent } & Sulfur & 4 & 1.2 & - \\
\hline & Peroxide & - & - & 5 \\
\hline \multirow[t]{4}{*}{ Vulcanization accelerator } & MBTS & 4 & 4 & - \\
\hline & Dithiobis(benzothiazole) & & & \\
\hline & TMTD & 2 & 2 & - \\
\hline & Tetramethylthiuram.disulfide & & & \\
\hline \multirow[t]{2}{*}{ Co-reticulation agent } & TAC 70 & - & - & 2 \\
\hline & Triallyl cyanurate $70 \%$ & & & \\
\hline
\end{tabular}

\subsection{Water sorption experiments}

All sorption measurements were made at $70^{\circ} \mathrm{C}$. Measurements in wet atmosphere (typically between 0 and $95 \% \mathrm{RH}$ ) were realized with an IGAsorp dynamic sorption analyzer from Hiden Isochema Co. This analyzer is composed of a climatic chamber equipped with an ultra-sensitive microbalance measuring changes in the sample mass as a function of temperature and relative humidity. The moisture content in the chamber is set between 0 and $98 \% \mathrm{RH}$ by mixing wet $(100 \% \mathrm{RH})$ and dry $(0 \% \mathrm{RH})$ nitrogen streams. In addition, the temperature is precisely controlled using a continuous fluid circulation via a loop inside the chamber.

Samples were suspended by a hook to the microbalance in order to maximize their initial mass and thus, to increase the sensitivity of the microbalance up to $\pm 0.2 \mu \mathrm{g}$. Before any sorption experiment, the samples were dried at $70^{\circ} \mathrm{C}$ in a $0 \% \mathrm{RH}$ atmosphere (at least $6 \mathrm{~h}$ ) in order to remove any traces of water adsorbed on their surface until the establishment of a horizontal baseline, corresponding to the mass of the fully dry material. It should be noted that the IGAsorp device is also equipped with a special oven capable of heating the samples at high temperature (up to $350^{\circ} \mathrm{C}$ ) when they cannot be quickly dried at the sorption temperature. However, such an oven was not necessary in this study.

Once completed this preliminary drying stage, the moisture was introduced at the desired relative humidity in the already heated climatic chamber. The changes in the sample mass were directly monitored in a computer and recorded throughout the test (recording during $5 \mathrm{~h}$ for each humidity).

Measurements in fully saturated wet atmosphere (i.e. denoted as $100 \% \mathrm{RH}$ ) were realized by immersion in pure distilled water. The samples were removed periodically from the bath to be manually weighted on a common laboratory microbalance. Before weighting, the samples were wiped with Joseph paper to remove any traces of water flowing on their surface.

\subsection{Definition of water uptake}

Since water is far below its critical point $\left(T_{C}=374{ }^{\circ} \mathrm{C}\right)$, the pertinent environmental parameter is the water activity. For wet atmospheres, this latter is defined as:

$a=\frac{P_{\text {water }}}{P_{\text {sat }}}=\frac{R H}{100}$

with $\mathrm{P}_{\text {water }}$ : the partial pressure of water vapor in the atmosphere, $\mathrm{P}_{\text {sat }}$ : the saturated vapor pressure of pure water, and $\mathrm{RH}$ : the relative humidity expressed in percent.

According to literature [3], immersion in water solution is equivalent to exposure to the fully saturated wet atmosphere above the solution. Therefore, in pure distilled water, it may be written as: $\mathrm{a}=1$.

Water uptake $\Delta \mathrm{m}$ (expressed in wt\%) is defined as:

$\Delta m=\frac{W_{\text {water }}}{W_{0}} * 100$

with $\mathrm{W}_{\text {water }}$ : mass of sorbed water and $\mathrm{W}_{0}$ : mass of the dry sample (in $\mathrm{g}$ ).

\section{Experimental results}

Fig. 2 presents the raw experimental data obtained in the 0-0.95 activity range at $70^{\circ} \mathrm{C}$ for the three EPDMs under study. All measurements are well-defined with an excellent signal to noise ratio. The initial part of all sorption curves is linear when they are plotted in function of the square root of time, indicating that a common Fick's diffusion process proceeds in all EPDMs.

In a first approach, Crank's mathematical decomposition was used to tentatively simulate all these experimental curves. As expected, Crank's model accounts for the initial straight-line and thus, gives access to the value of the coefficient of water diffusion. In contrast, some deviations between theory and experiments can be observed at longer times. The simulations call for several comments:

- In the 0-0.5 activity range, Crank's model reproduces faithfully the entire sorption curves until the final saturation plateau. The coefficient of water diffusion takes an almost constant value around $2.5 \times 10^{-10} \mathrm{~m}^{2} \mathrm{~s}^{-1}$ regardless the water activity for all studied EPDMs (see Table 2). This result is a sound argument in favor of the validity of Fick's law. Since this average value is in the same order of magnitude, but between 2 and 5 times lower than that reported for PE [6], the presence of diffusion traps is suspected in the three EPDMs under study. According to the literature [4,5,15-17], two main trapping mechanisms can be considered: i) The establishment of intense interactions (hydrogen bonds) with polar groups coming from vulcanization additives (ZnO [11], stearic acid [12], $\alpha$-cumyl alcohol originating from peroxide by-products $[13,14]$, etc.) or formed during

$$
\begin{aligned}
& {\left[\mathrm{S}_{1} \ldots \mathrm{H}_{2} \mathrm{O}\right] \rightarrow \mathrm{S}_{1}+\mathrm{H}_{2} \mathrm{O}} \\
& \mathrm{H}_{2} \mathrm{O} \rightarrow \text { migration until } \mathrm{S}_{2} \\
& \mathrm{~S}_{2}+\mathrm{H}_{2} \mathrm{O} \rightarrow\left[\mathrm{S}_{2} \ldots \mathrm{H}_{2} \mathrm{O}\right]
\end{aligned}
$$

Fig. 1. Three-step mechanism for water diffusion into polymer matrices. $S_{1}$ and $S_{2}$ designate two neighboring hydrophilic sites and $\left[\mathrm{S}_{\mathrm{i}} \cdots \mathrm{H}_{2} \mathrm{O}\right]$ a hydrogen bonded waterpolymer complex. 

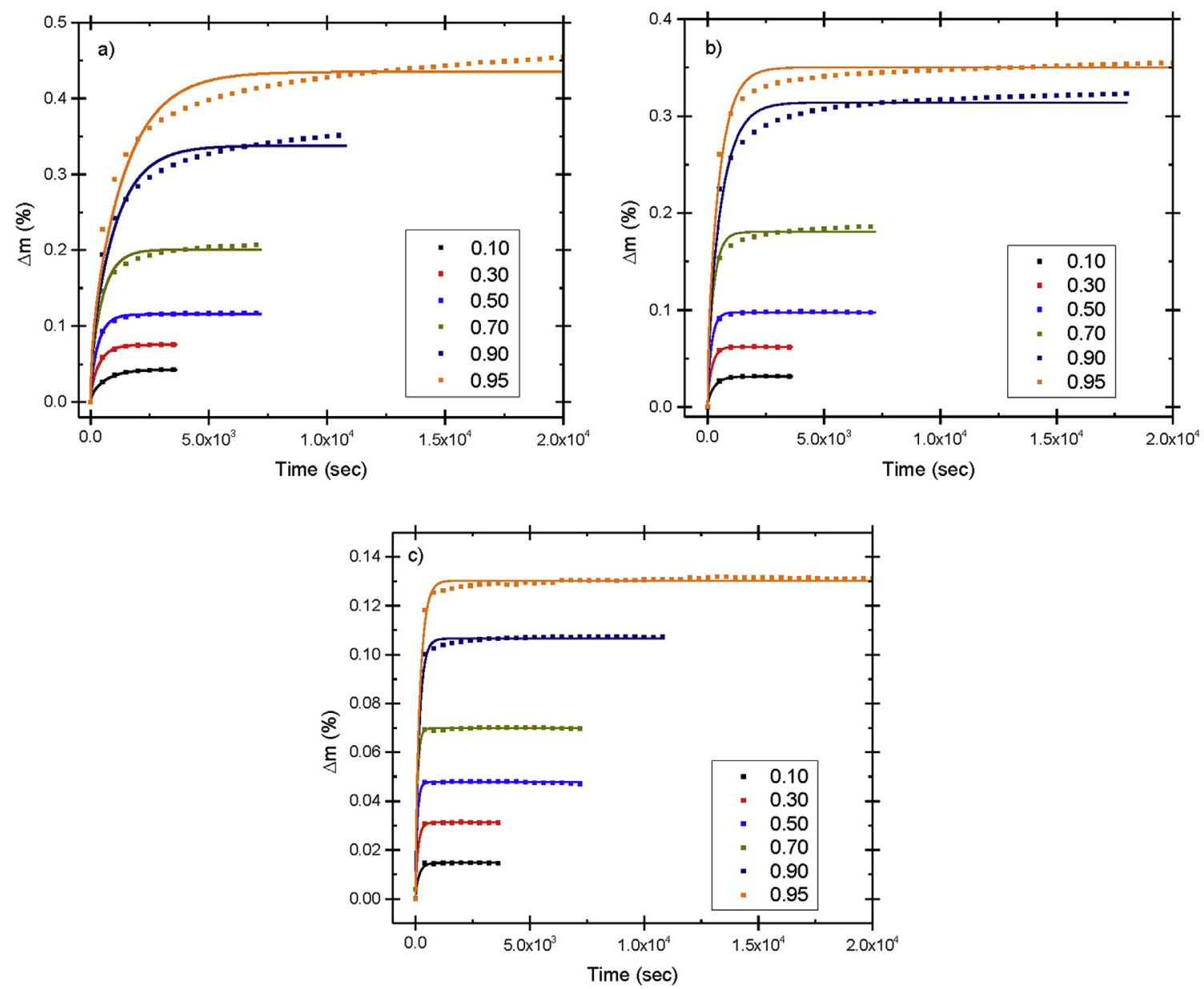

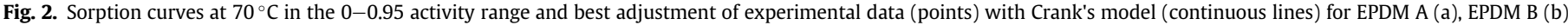
and EPDM C (c).

Table 2

Average values of coefficients of water diffusion at $70{ }^{\circ} \mathrm{C}$ (expressed in $\mathrm{m}^{2} . \mathrm{s}^{-1}$ ) in the 0-0.5 activity range for the three EPDMs under study.

\begin{tabular}{lll}
\hline EPDM A & EPDM B & EPDM C \\
\hline $1.2 \pm 0.3 \times 10^{-10}$ & $1.4 \pm 0.3 \times 10^{-10}$ & $3.0 \pm 1.0 \times 10^{-10}$ \\
\hline
\end{tabular}

the processing operation (oxidation products); ii) The formation of water clusters in free volume holes.

- In contrast, at activities higher than 0.5 , it can be observed small deviations between theory and experiment, especially in the transition zone between the transient (initial straight-line) and steady regimes (final saturation plateau), which seem to be more and more marked when increasing the water activity. In addition, the coefficient of water diffusion becomes a decreasing function of the water activity. This general trend was confirmed by performing sorption experiments in immersion in pure distilled water $(\mathrm{a}=1)$ on all EPDMs, for which coefficients of water diffusion even lower by one order of magnitude were determined at $70^{\circ} \mathrm{C}$ (Fig. 3). Referring to the trapping mechanisms previously mentioned, this behavior can be attributed to solely water clustering.

Fig. 4 gives the equilibrium water uptake at $70^{\circ} \mathrm{C}$ of the three EPDMs under study as a function of the water activity. It appears clearly that these sorption isotherms are linear only in the low

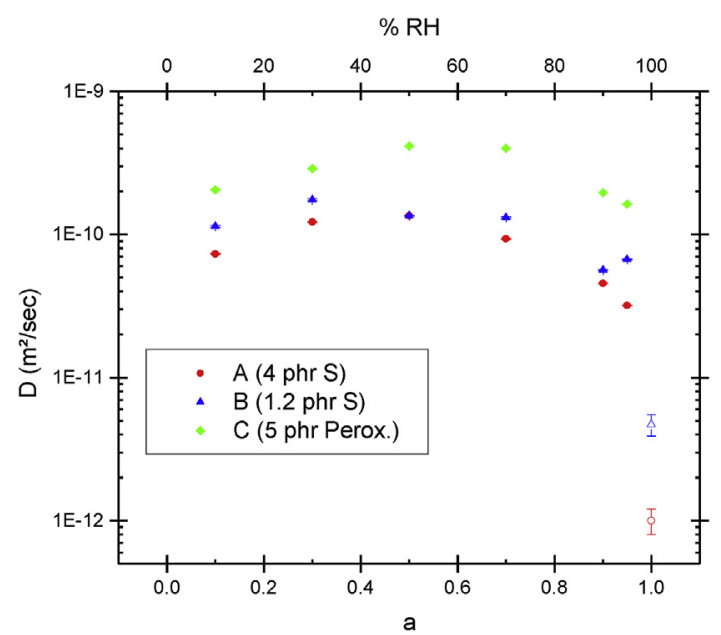

Fig. 3. Coefficients of water diffusion at $70{ }^{\circ} \mathrm{C}$ and throughout the whole activity range for the three EPDMs under study (determined with Crank's model according to Fig. 2). The empty symbols point out measurements carried out in immersion in pure distilled water.

activity range (typically between 0 and 0.5 ) and display a positive concavity at high activity (typically when a $>0.5$ ). According to the literature [3,27], this peculiar sorption behavior is due to the 


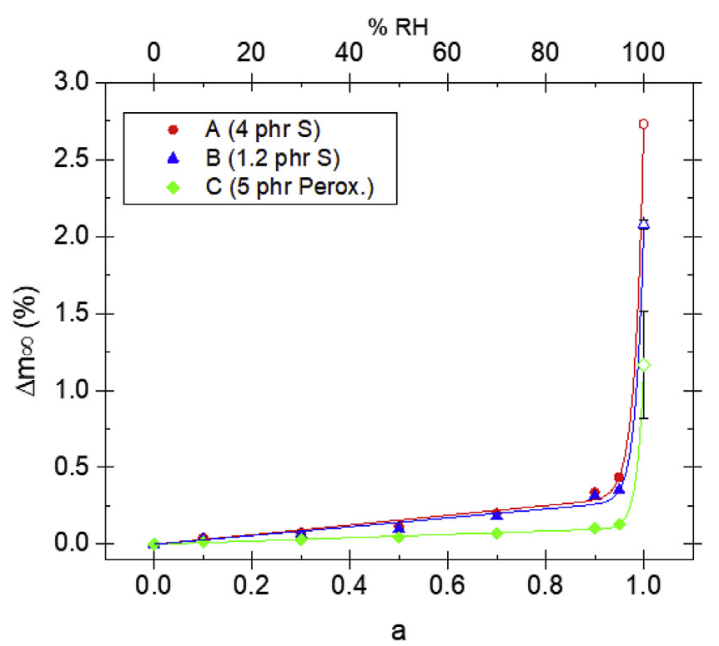

Fig. 4. Sorption isotherms at $70^{\circ} \mathrm{C}$ of the studied EPDMs throughout the whole activity range. The empty symbols point out measurements carried out in immersion in pure distilled water.

formation of water clusters. As reported in introduction, this result is not surprising because free volume holes are much larger in crosslinked EPDMs than for instance in PE, thus offering the possibility to several (at least six) water molecules to be inserted in a hole. This large difference in free volume could also explain why, although they are almost hydrophobic, the studied EPDMs display much higher values of equilibrium water uptake than common PE. These values are typically ranged between 1.2 and $2.7 \mathrm{wt} \%$ for the studied EPDMs when immersed in pure distilled water at $70^{\circ} \mathrm{C}$ (see empty symbols given for $\mathrm{a}=1$ in Fig. 4). They are thus about 100-200 times higher than for PE immersed in pure distilled water at similar temperature [6].

The impact of the EPDM formulation (nature and content of the crosslinking system) on all these experimental results is extremely low. Those are clearly of the second order of magnitude. Nevertheless, the coefficient of water diffusion is slightly higher and the equilibrium water uptake slightly lower in the peroxide crosslinked EPDM (EPDM C) than in sulfur vulcanized EPDMs (EPDM A and EPDM B). For all studied EPDMs, it is possible to identify that more $D$ is lifted $\left(D_{C}>D_{B}>D_{A}\right)$, more $\Delta m_{\infty}$ is lower $\left(\Delta \mathrm{m}_{\mathrm{C}}<\Delta \mathrm{m}_{\mathrm{B}}<\Delta \mathrm{m}_{\mathrm{A}}\right)$. These small differences observed in sorption behavior between EPDMs could be attributed to a small difference in formulation rather than in free volume. Indeed, it is found that $\Delta \mathrm{m}_{\infty}$ varies in the opposite direction than expected for an increasing crosslinking density (for instance, if comparing EPDMs B and $\mathrm{A}$ ). On the contrary, this result seems in satisfying agreement with the molar contributions to cohesive energy density and molar attraction constants reported in the literature for usual chemical groups. Indeed, according to Van Krevelen and Te Nijenhuis [31], sulfur structures would be slightly less apolar than aliphatic hydrocarbon groups. Thus, these former would establish a few more interactions with water molecules, which would explain the small increase in $\Delta \mathrm{m}_{\infty}$ with the sulfur ratio. In addition, as previously reported the literature [5], these additional interactions would also hinder the migration of water molecules into the polymer volume, which would also explain the small decrease in D with the sulfur ratio.

Finally, the values of water permeability $\mathrm{P}_{\mathrm{e}}$ (i.e. product of $\mathrm{D}$ by $\Delta \mathrm{m}_{\infty}$ ) determined at $70^{\circ} \mathrm{C}$ for the three studied EPDMs were plotted in Fig. 5 as a function of water activity and compared to the values reported between 25 and $70{ }^{\circ} \mathrm{C}$ in $100 \% \mathrm{RH}$ for pure $\mathrm{PE}$ in the literature $[6,32-34]$. In the $0-0.8$ activity range, permeability takes

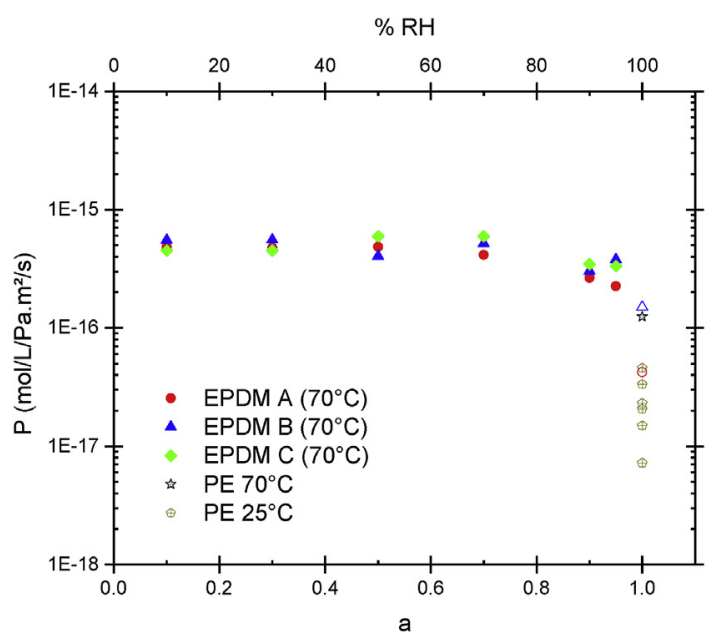

Fig. 5. Water permeabilities at $70^{\circ} \mathrm{C}$ and throughout the whole activity range for the three EPDMs under study. The empty symbols point out measurements carried out in immersion in pure distilled water. Comparison with literature data between 25 and $70^{\circ} \mathrm{C}$ for PE [6,32-34].

Table 3

Average values of coefficients of water permeability at $70^{\circ} \mathrm{C}$ (expressed in mol. $\left.\mathrm{m}^{2} \cdot \mathrm{L}^{-1} \cdot \mathrm{s}^{-1} \cdot \mathrm{Pa}^{-1}\right)$ in the $0-0.8$ activity range for the three EPDMs under study.

\begin{tabular}{lll}
\hline EPDM A & EPDM B & EPDM C \\
\hline $4.6 \pm 0.3 \times 10^{-16}$ & $5.0 \pm 0.7 \times 10^{-16}$ & $5.2 \pm 0.8 \times 10^{-16}$ \\
\hline
\end{tabular}

an almost constant value around $5.1 \times 10^{-16} \mathrm{~mol} \mathrm{~m}{ }^{2} \mathrm{~L}^{-1} \cdot \mathrm{s}^{-1} \cdot \mathrm{Pa}^{-1}$ for all studied EPDMs (see Table 3 ). In contrast, at activities higher than 0.8 , it can be observed a slow decrease in permeability up to a minimal value ranged between $4.2 \times 10^{-17}$ (for EPDM A) and $1.5 \times 10^{-16} \mathrm{~mol} \mathrm{~m}^{2} \mathrm{~L}^{-1} \cdot \mathrm{s}^{-1} \cdot \mathrm{Pa}^{-1}$ (for EPDM B) when increasing the water activity. These two latter values border the single value at $70{ }^{\circ} \mathrm{C}$ in $100 \% \mathrm{RH}\left(1.2 \times 10^{-16} \mathrm{~mol} \mathrm{~m}^{2} \mathrm{~L}^{-1} \cdot \mathrm{s}^{-1} \cdot \mathrm{Pa}^{-1}\right)$ available in the literature for PE [6]. Thus, the permeability is not the relevant property to discriminate and analyze the differences in water absorption behavior between EPDMs and PE, unlike diffusivity and equilibrium water uptake. In addition, the permeability appears to be less sensitive to water clustering since the regime change occurs at higher activity (0.8 against 0.5 for diffusivity and equilibrium water uptake).

To conclude on this first analysis part of experimental results, it can be considered that the deviations between Crank's model and the experimental data are within the experimental scattering. As a consequence, it can be considered that Fick's law gives a satisfying estimation of the coefficient of water diffusion throughout the whole water activity range, so more complex models are not necessary for modeling water diffusion in EPDMs. In addition, since the water permeability takes a constant value in the $0-0.8$ activity range, $\mathrm{D}$ can be directly deduced from the value of the equilibrium water uptake.

Next parts of this article are devoted to the understanding and modeling of the sorption isotherms of the three EPDMs under study.

\section{Modelling of sorption isotherms}

As stated in introduction, it seems relevant to use Park's model $\left(\Delta m_{\infty}=H^{*} a+B^{*} a^{n}\right)$ for modelling the sorption isotherms. This model is an extension of Henry's law, so the model parameters were determined incrementally. In a first stage, Henry's constant $\mathrm{H}$ 


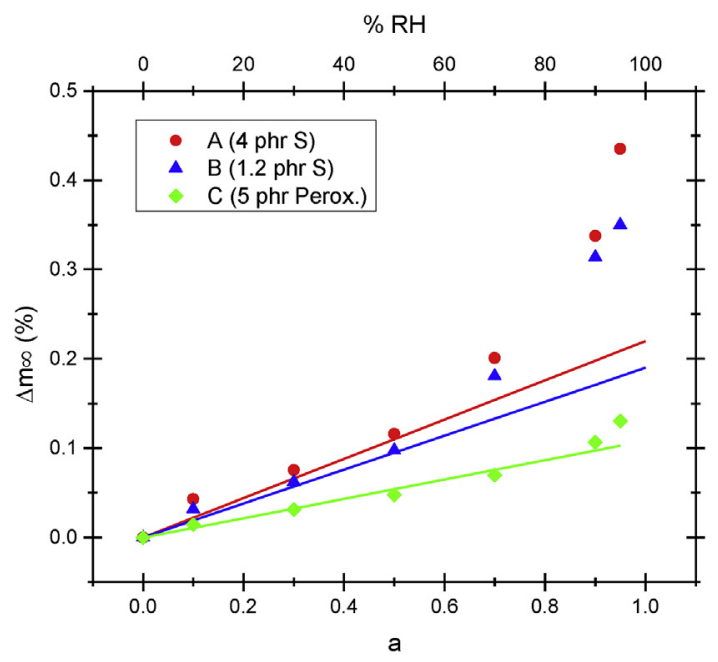

Fig. 6. Modelling with Henry's law of the sorption isotherms at $70{ }^{\circ} \mathrm{C}$ in the $0-0.95$ activity range.

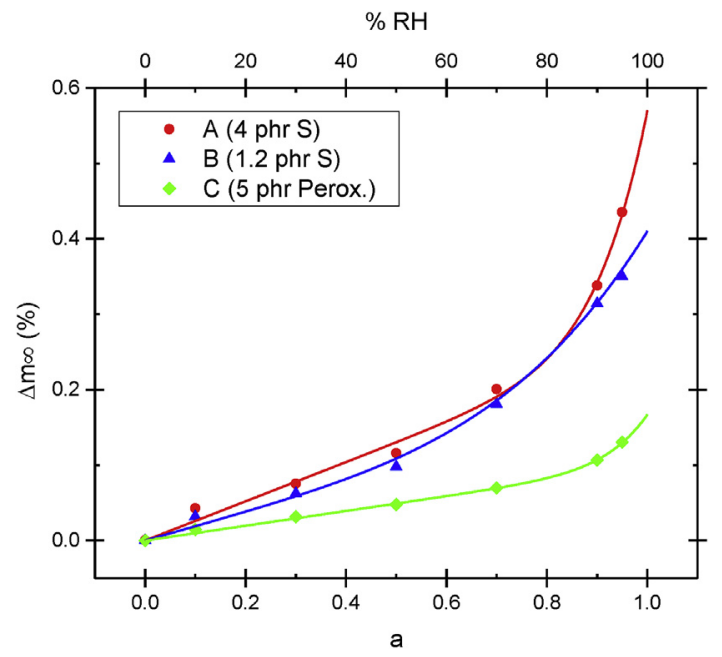

Fig. 7. Modelling with Park's model of the sorption isotherms at $70^{\circ} \mathrm{C}$ in the $0-0.95$ activity range.

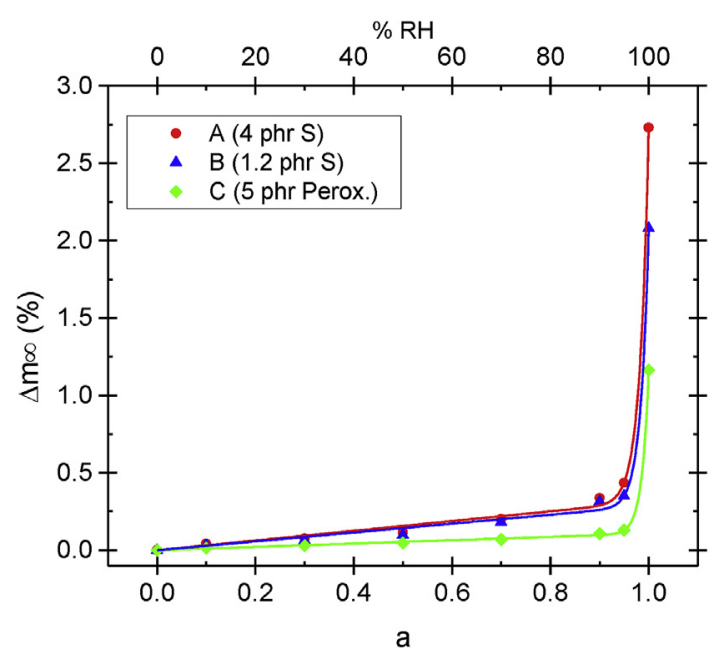

Fig. 8. Modelling with Park's model of the sorption isotherms at $70^{\circ} \mathrm{C}$ throughout the whole activity range. was determined from the linear part of the sorption isotherms in the $0-0.5$ activity range in order to quantify the water-polymer interactions, as shown in Fig. 6. The average values obtained for $\mathrm{H}$ are: $0.22 \mathrm{~g} / \mathrm{g}$ for EPDM A; $0.19 \mathrm{~g} / \mathrm{g}$ for EPDM B and $0.11 \mathrm{~g} / \mathrm{g}$ for EPDM $C$. These values confirm that the water-polymer interactions are slightly higher in sulfur vulcanized EPDMs (EPDM A and EPDM B) than in the peroxide vulcanized EPDM (EPDM C).

In second stage, parameters $B$ and $n$ were determined from the entire shape of the sorption isotherms in order to quantify the cluster sizes (number of water molecules associated in cluster). First, only in the $0-0.95$ activity range, as shown in Fig. 7. Indeed, when the water immersion condition $(a=1)$ is not considered, a single couple of values for parameters $\mathrm{B}$ and $\mathrm{n}$ was found to simulate accurately all experimental data for each EPDM individually (see Table 4). In that case, the average values obtained for $n$ in Park's model are: 10, 4 and 12 for respectively EPDMs A, B and C. These values are consistent with the rough estimation made in introduction with the free volume theory (clusters would be composed of about 6 water molecules). These values seem to fully confirm the proposal of scenario.

In the last stage, new attempts of modelling were done, but this time throughout the whole activity range (see Fig. 8), but trying to keep constant the previous values determined for $\mathrm{H}$ and $\mathrm{B}$. In other words, it was tried to determine the "best value" of n accounting for the sorption isotherms throughout the whole activity range (i.e. between 0 and 1). Unfortunately, to simulate the data in pure distilled water, the values of $\mathrm{H}$ and $\mathrm{B}$ had to be substantially modified. The average values thus obtained for $\mathrm{n}$ are reported in Table 5. In that case, the values of $\mathrm{n}$ are ten times higher than previously: 55, 58 and 71 for respectively EPDMs A, B and C. This result could indicate a much larger swelling than expected when samples are immersed in pure distilled water. The examination of samples after their removing from the water bath confirmed this suspicions, but the real causes of this exacerbated swelling remain unknown. It can be thus concluded that, for vulcanized EPDMs, immersion in water solution is more drastic than exposure to fully saturated wet atmosphere. In other words, in that case, immersion in pure distilled water is not eligible to the usual definition: " $\mathrm{a}=1$ ".

\section{Conclusion}

The mains results obtained in this study can be summarized as follows:

- In unfilled vulcanized EPDMs, water diffusivity is lower and equilibrium water uptake is higher than in PE. The impact of the EPDM formulation (nature and content of crosslinking agent) is extremely low on these two properties.

- Water permeability (i.e. the product of $\mathrm{D}$ by $\Delta \mathrm{m}_{\infty}$ ) is similar in EPDMs and PE. Thus, it is not the relevant property to discriminate and analyze the differences in water absorption behavior between EPDMs and PE, unlike diffusivity and equilibrium water uptake.

- In the 0-0.5 activity range, EPDMs obey the usual Fick and Henry's laws.

Table 4

Parameters of Park's model (H, B and $n)$ and coefficient of standard deviation $\left(\mathrm{r}^{2}\right)$ determined for the three EPDMs under study at $70^{\circ} \mathrm{C}$ in the $0-0.95$ activity range.

\begin{tabular}{lll}
\hline EPDM A & EPDM B & EPDM C \\
\hline $\mathrm{H}=0.26 \mathrm{~g} / \mathrm{g} \pm 0.01$ & $\mathrm{H}=0.19 \mathrm{~g} / \mathrm{g} \pm 0.03$ & $\mathrm{H}=0.098 \mathrm{~g} / \mathrm{g} \pm 0.003$ \\
$\mathrm{~B}=0.31 \pm 0.05$ & $\mathrm{~B}=0.22 \pm 0.02$ & $\mathrm{~B}=0.07 \pm 0.01$ \\
$\mathrm{n}=10 \pm 3$ & $\mathrm{n}=4 \pm 1$ & $\mathrm{n}=12 \pm 3$ \\
$\mathrm{r}^{2}=0.99599$ & $\mathrm{r}^{2}=0.99747$ & $\mathrm{r}^{2}=0.99788$ \\
\hline
\end{tabular}


Table 5

Parameters of Park's model (H, B and $n$ ) and coefficient of standard deviation $\left(\mathrm{r}^{2}\right)$ determined for the three EPDMs under study at $70^{\circ} \mathrm{C}$ throughout the whole activity range.

\begin{tabular}{lll}
\hline EPDM A & EPDM B & EPDM C \\
\hline $\mathrm{H}=0.31 \mathrm{~g} / \mathrm{g} \pm 0.03$ & $\mathrm{H}=0.28 \mathrm{~g} / \mathrm{g} \pm 0.03$ & $\mathrm{H}=0.108 \mathrm{~g} / \mathrm{g} \pm 0.005$ \\
$\mathrm{~B}=2.41 \pm 0.04$ & $\mathrm{~B}=1.65 \pm 0.05$ & $\mathrm{~B}=1.056 \pm 0.008$ \\
$\mathrm{n}=55 \pm 5$ & $\mathrm{n}=58 \pm 10$ & $\mathrm{n}=71 \pm 5,5$ \\
$\mathrm{r}^{2}=0.99917$ & $\mathrm{r}^{2}=0.9980$ & $\mathrm{r}^{2}=0.99983$ \\
\hline
\end{tabular}

- At higher activities than 0.5 , the formation of water clusters is responsible for the deviations of the water sorption behavior of EPDMs from these two laws. In wet atmospheres, clusters are composed of about $8 \pm 4$ water molecules, i.e. they are approximately of the size of free volume holes.

- In pure distilled water, an exacerbated swelling occurs leading to a significant increase in the cluster sizes.

\section{References}

[1] J.A. Barrie, Water in polymers, in: J. Crank, G.S. Park (Eds.), Diffusion in Polymers, Academic Press, London \& New York, 1968, pp. 259-313.

[2] D.W. Van Krevelen, P.J. Hoftyser (Eds.), Properties of Polymers. Their Estimation and Correlation with Chemical Structure. Their Numerical Estimation an Prediction from Additive Group Contributions, fourth ed., Elsevier, Amsterdam, 2009, pp. 655-702. Chap. 18.

[3] X. Colin, J. Verdu, Humid ageing of organic matrix composites, in: P. Davies, Y.D.S. Rajapakse (Eds.), Solid Mechanics and its Applications, vol. 208, Springer, Dordrecht, 2014, pp. 47-114. Durability of composites in a marine environment.

[4] X. Colin, Nonempirical kinetic modelling of non-Fickian water absorption induced by a chemical reaction in epoxy-amine networks, in: P. Davies, Y.D.S. Rajapakse (Eds.), Solid Mechanics and its Applications, vol. 245, Springer, Dordrecht, 2018, pp. 1-18. Durability of composites in a marine environment 2 .

[5] A. Tcharkhtchi, P. Bronnec, J. Verdu, Water absorption characteristics of diglycidyllether of butane diol-3,5-diethyl-2,4-diaminotoluene networks, Polymer 41 (2000) 5777-5785.

[6] D.W. McCall, D.C. Douglass, L.L. Blyler Jr., G.E. Johnson, L.W. Jelinski, H. Blair, Solubility and diffusion of water in low-density polyethylene, Macromolecules 17 (1984) 1644-1649.

[7] P.E Cassidy, T.M. Aminabhavi, C.M. Thompson, Water permeation through elastomers and plastics, Rubber Chem. Technol. 56 (3) (1983) 594-618.

[8] E.E.B. Meuleman, J.H.A. Willemsen, M.H.V. Mulder, H. Strathmann, EPDM as a selective membrane material in pervaporation, J. Membr. Sci. 188 (2001) 235-249.

[9] Parker O-Ring Handbook, Parker Hannifin Corporation, O-Ring Division, Lexington (Kentucky), 2001.

[10] T.C. Chivers, A.F. George, EPDM and fluorocarbon seal materials: a comparison of performance for nuclear fuel transport flasks, in: Proceedings of the $14^{\text {th }}$ International Symposium on the Packaging and Transport of Radioactive Materials (PATRAM), Berlin, 2004. Sept 20-24, paper \# 213.

[11] T. Charinpanitkul, W. Suthabanditpong, H. Watanabe, T. Shirai, K. Faungnawakij, N. Viriya-empikul, M. Fuji, Improved hydrophilicity of zinc oxide-incorporated layer-by-layer polyelectrolyte film fabricated by dip coating method», J. Ind. Eng. Chem. 18 (4) (2012) 1441-1445.
[12] G.G. Roberts (Ed.), Langmuir-Blodgett Films, Plenum Press, New-York, 1990, 18.

[13] T. Shikata, M. Okuzono, Are all polar molecules hydrophilic? Hydration numbers of ketones and esters in aqueous solution, J. Phys. Chem. B 117 (25) (2013) 7718-7723.

[14] J. Sahyoun, A. Crepet, F. Gouanve, L. Keromnes, E. Espuche, Diffusion mechanism of byproducts resulting from the peroxide crosslinking of polyethylene, J. Appl. Polym. Sci. 134 (9) (2006), 44525.

[15] M. Cohen, D. Turnbull, Molecular transport in liquids and glasses, J. Chem. Phys. 31 (1959) 1164-1169.

[16] J. Ventras, J. Duda, Diffusion in polymer-solvent systems II. Predictive for the dependence of diffusion coefficient on temperature, concentration, molecular weight, J. Polym. Sci., Polym. Phys. Ed. 15 (1977) 417-439.

[17] J. Ventras, J. Duda, Difusion in polymer-solvent systems. I. Re-examination of the free volume theory, J. Polym. Sci., Polym. Phys. Ed 15 (1977) 403-416.

[18] C.L. Soles, A. Yee, A discussion of the molecular mechanisms of moisture transport in epoxy resins, J. Polym. Sci., Part B: Polym. Phys. 38 (2000) $792-802$.

[19] P. Flory, J. Rehner, Statiscal mechanics of crosslinked polymer networks II. Swelling, J. Chem. Phys. 11 (1943) 521-526.

[20] P. Budd, N. McKeown, D. Fritsch, Free volume and intrinsic microporosity in polymers, J. Mater. Chem. 15 (120) (2005) 1977-1986.

[21] M. Baba, J. Nedelec, J. Lacoste, J. Gardette, M. Morel, Crosslinking of elastomers resulting form ageing: use of thermoporosimetry to characterise the polymeric networlk with n-heptane as condensate, Polym. Degrad. Stab. 80 (12) (2003) 305-313.

[22] Y. Jean, Positron annihilation spectroscopy for chemical analysis : a novel probe for microstructural analysis of polymers, Microchem. J. 42 (1990) $72-102$.

[23] D. Kilburn, D. Bamford, T. Lüpke, G. Dlubek, T. Menke, M. Alam, Free volume and glass transition in ethylene/1-octene copolymers : positron lifetime studies and dynamic mechanical analysis, Polymer 43 (2002) 6973-6983.

[24] J. Crank (Ed.), The Mathematics of Diffusion, Oxford University Press, Oxford, 1975, p. 48.

[25] B. Lutz, Z. Guan, L. Wang, F. Zhang, Z. Lü, Water absorption and water vapor permeation characteristics of HTV silicone rubber material, IEEE Electr. Insul. (2012) 478-482.

[26] D.E. Nasha, E. Gomaa, S. Abd-El-Messieh, Study of electrical, mechanical and nanoscale free volume properties of NBR and EPDM rubber reinforced by bentonite or kaolin, J. Polym. Sci. Part B 47 (2009) 1825-1838.

[27] S. Basu, U. Shivhare, A. Mujumdar, Models for sorption isotherms for foods : a review, Dry. Technol. 24 (2006) 917-930.

[28] C. Berg, Development of B.E.T.-like models for sorption of water on foods, theory and relevance, in: D. Simatos, J.L. Multon (Eds.), Properties of Water in Foods. In Relation to Quality and Stability. NatoScience Series E. Dordrecht: Martinus Nijhoff Publishers, 1985, pp. 119-131.

[29] C. Shen, G. Springer, Moisture absorption and desorption of composite materials, J. Compos. Mater. 10 (1976) 2-20.

[30] G.S. Park, Transport Principles-Solution, diffusion and permeation in polymer membranes, in: P.M. Bungay, H.K. Lonsdale, M.N. Pinho (Eds.), Synthetic Membranes: Science, Engineering and Applications, Reidel Publishing Company, Dordrecht, 1986, pp. 57-107.

[31] D.W. Van Krevelen, P.J. Hoftyser (Eds.), Properties of Polymers. Their Estimation and Correlation with Chemical Structure. Their Numerical Estimation and Prediction from Additive Group Contributions, fourth ed., Elsevier, Amsterdam, 2009, pp. 189-227. Chap. 7.

[32] P.M. Doty, W.H. Aiken, H. Mark, Water vapor permeability of organic films, Ind. Eng. Chem. Anal. Ed. 16 (1944) 686-690.

[33] P.E. Rouse Jr., Diffusion of vapors in films, J. Am. Chem. Soc. 69 (5) (1947) 1068-1073.

[34] P.M. Hauser, A.D. McLaren, Permeation through and sorption of water vapor by high polymers, Ind. Eng. Chem. Ed. 40 (1948) 112-117. 